\title{
Formation of spherical cancer stem-like cell colonies with resistance to chemotherapy drugs in the human malignant fibrous histiocytoma NMFH-1 cell line
}

\author{
LIANG DENG ${ }^{*}$, DEJIAN LI* ${ }^{*}$,WENGUANG GU, AIGUO LIU and XIANGYANG CHENG \\ Department of Orthopedic Surgery, First Affiliated Hospital of Harbin Medical University, \\ Harbin, Heilongjiang 150001, P.R. China
}

Received October 23, 2014; Accepted August 20, 2015

DOI: $10.3892 / \mathrm{ol} .2015 .3712$

\begin{abstract}
Various human cancers have been revealed to contain cancer stem-like cells (CSCs) and the spherical colonies that possess stem-like properties and cancer-initiating abilities. Malignant fibrous histiocytoma (MFH) is a common soft-tissue sarcoma, and is considered to be a myxoma due to the observed high-grade lesions. In the present study, the spherical colonies were isolated from a human MFH cell line NMFH-1 using the sphere culture system. These colonies demonstrated stem-like properties, with the ability of self-renewal and strong drug-resistance to doxorubicin and cisplatin. In addition, verapamil, an adenosine triphosphate binding cassette protein transporter protein (ABCG2) inhibitor, enhanced the efficacy of the aforementioned chemotherapy agents. These colonies also demonstrated an increased expression of embryonic stem genes, including Oct3/4, signal transducer and activator of transcription 3, sex determining region Y-box 10 and ABCG2, and stem cell-associated surface markers, such as cluster of differentiation (CD)44 and CD133. These results indicated that NMFH-1 lesions contain cancer stem-like cell populations that demonstrate strong drug resistance, and verapamil enhanced the efficacy of the chemotherapy agents.
\end{abstract}

\section{Introduction}

The cancer stem-like cell (CSC) theory hypothesizes that tumors contain a small subpopulation of cancer cells that share numerous properties with normal stem cells, including proliferative potential and self-renewal (1). These rare

Correspondence to: Dr Wenguang Gu, Department of Orthopedic Surgery, First Affiliated Hospital of Harbin Medical University, 23 Youzheng Street, Harbin, Heilongjiang 150001, P.R. China E-mail: guwenguang@hotmail.com

*Contributed equally

Key words: tumor, cancer stem cell, bone and soft tissue sarcoma, malignant fibrous histiocytoma, drug resistance, verapamil stem-like tumor initiators are considered to be associated with initiating and maintaining the growth of tumors, and may be responsible for the local recurrence and distant metastasis of tumors (1). Previous studies have indicated that CSCs exist in numerous human tumors, including hematopoietic cancer (2), brain tumors (3), breast cancer (4), melanoma (5) and bone sarcoma (6,7). Advanced methods and techniques have contributed to the identification of CSCs (2). These methods include the detection of specific surface markers that are selectively expressed on CSCs, but not on the majority of tumor cells, serum-free suspension culture medium for colony formation in vitro and a unique pattern of staining with certain dyes, including Hoechst 33342, for detecting side population (SP) cells (2-5): The characteristics of side population cells include proliferative potential and self-renewal.

Previous studies have revealed that specific surface molecules, including cluster of differentiation (CD)133 and CD44, may be markers for certain CSC populations (8-11). Several studies have indicated that CSCs may demonstrate the ability of increased resistance to chemotherapy, due to the high expression of specific drug transporters, including multidrug resistance protein 1 and adenosine triphosphate (ATP)-binding cassette (ABC) sub-family G member 2 (ABCG2) $(12,13)$. Certain cell enzymes have also been demonstrated to be useful molecules for the selection and detection of CSCs, and aldehyde dehydrogenase (ALDH) 1 is one of the possible candidates for a stem cell marker that may be used for the isolation of CSCs from tumors in cancers that include leukemia, breast cancer and sarcoma (14-16).

Although the mechanisms of drug resistance in CSCs are poorly understood, previous studies have revealed that these may be associated with the ABC drug transporters $(17,18)$.

CSC markers remain limited, but the sphere culture system is particularly useful as a functional approach to enrich the potential CSC subpopulations which including proliferative potential and self-renewal. (6). The sphere culture system, which comprises stressful growth conditions of serum starvation and anchorage independence, is frequently used to identify and enrich stem and progenitor cells by eliminating the differentiated cells that are unable to survive (6). Reynolds and Weiss (19) first employed this system to demonstrate that the adult mammalian brain contained cells that gave 
rise to neurosphere clones. This method is also termed the neurosphere/sarcomaspere culture system. Previous studies have demonstrated that spherical forming colonies derived from various tumors demonstrated stem-like properties with the ability of self-renewal, increased expression of certain embryonic stem (ES) genes, and tumorigenicity in mouse models $(6,7,20-23)$. The present study aimed to detect SP and $\mathrm{ALDH}^{+}$cell populations in human fibrosarcoma HT1080 and malignant fibrous histiocytoma (MFH) NMFH-1 cells.

\section{Materials and methods}

Cell lines and culture. The human synovial sarcoma SW982 cells and fibrosarcoma HT1080 cell lines were obtained from the American Type Culture Collection (Manassas, VA, USA). The novel myxofibrosarcoma NMFH-1 cell line, which was considered to be a myxoid variant of $\mathrm{MFH}$, was provided by Dr. Akira Ogose (Division of Orthopedic Surgery, Niigata University Graduate School of Medical and Dental Sciences, Niigata, Japan) (24). The SW982 cells were maintained in Leibovitz's L-15 medium (Gibco Life Technologies, Carlsbad, CA, USA) supplemented with $10 \%$ fetal bovine serum (FBS; HyClone, Logan, UT, USA), the HT1080 cells were maintained in Dulbecco's modified Eagle's medium (DMEM; Gibco Life Technologies) supplemented with $10 \%$ FBS, and the NMFH-1 cells were maintained in RPMI-1640 medium (Gibco Life Technologies) supplemented with 10\% FBS. All cells were maintained at $37^{\circ} \mathrm{C}$ in a $5.0 \% \mathrm{CO}_{2}$ atmosphere.

Identification of SP cells. The cell suspensions were labeled with Hoechst 33342 dye (Sigma-Aldrich, St. Louis, MO, USA), using the method described by Goodell et al (25). Briefly, the cells were trypsinized and re-suspended in pre-warmed Leibovitz's L-15 medium, DMEM or RPMI-1640 medium supplemented with $5 \%$ FBS at a concentration of $1 \times 10^{6}$ cells $/ \mathrm{ml}$. Hoechst 33342 dye was added at a final concentration of $5.0 \mu \mathrm{g} / \mathrm{ml}$ in the presence or absence of $50 \mu \mathrm{M}$ verapamil (Sigma-Aldrich), which acts as an inhibitor of the $\mathrm{ABC}$ transporter. The cells were incubated at $37^{\circ} \mathrm{C}$ for $90 \mathrm{~min}$ with continuous agitation. At the end of the incubation, the cells were washed with ice-cold PBS supplemented with $5 \% \mathrm{FBS}$, centrifuged at $4^{\circ} \mathrm{C}$ and resuspended in ice-cold PBS containing 5\% FBS. Flow cytometry was performed using BD FACSAria II (BD Biosciences, Franklin Lakes, NJ, USA). The Hoechst 33342 dye was excited at $357 \mathrm{~nm}$ and the fluorescence was analyzed using a dual wavelength (blue, 402-446 nm; red, 650-670 nm).

Spherical colony formation assay. Monolayer cells at $\sim 70 \%$ confluence in RPMI medium supplemented with 10\% FBS were dissociated into single-cell suspensions using $0.25 \%$ trypsin and $0.05 \%$ EDTA (Sigma-Aldrich). The cells were then inoculated into B27-supplemented RPMI-1640 medium and $1 \%$ methylcellulose medium mixed with $10 \mathrm{ng} / \mathrm{ml}$ human recombinant epidermal growth factor (EGF) and $10 \mathrm{ng} / \mathrm{ml}$ basic fibroblast growth factor $(\beta \mathrm{FGF})$ at a cell density of $6 \times 10^{4}$ cells per well in ultra low attachment 6 -well plates (Corning Inc., Corning, NY, USA). EGF and $\beta F G F$ were purchased from PeproTech, Inc. (Rocky Hill, NJ, USA).

Fresh aliquots of EGF and $\beta F G F$ were added every other day. Subsequent to 7-12 days of culture, the colonies that contained $>40$ cells were quantitated by inverted phase contrast microscopy (Olympus CKX41; Olympus, Tokyo, Japan). Spherical colonies were dissociated and re-introduced into 96-well ultra low attachment plates at least 5 times, in normal medium and in anchorage-independent methylcellulose medium, to investigate the self-renewal ability of the cells through secondary sphere formation.

Aldefluor assay and detection of the ALDH $H^{+}$subpopulations by FACS. The Aldefluor (StemCell Technologies, Inc., Vancouver, BC, Canada) was used to detect cell populations with high ALDH enzymatic activity. The cells were labeled with Aldefluor reagent, according to the manufacturer's instructions. Briefly, cultures of NMFH-1 and SP cells were harvested by trypsin-EDTA and resuspended in Aldefluor assay buffer, containing $1 \mu \mathrm{mol} / 1$ of the ALDH substrate BODIPY aminoacetaldehyde (StemCell Technologies, Inc.) per $1 \times 10^{6}$ cells. The cells were then incubated for $30 \mathrm{~min}$ at $37^{\circ} \mathrm{C}$. As a negative control for each sample of cells, an aliquot was treated with $50 \mathrm{mmol} / \mathrm{l}$ 4-diethylaminobenzaldehyde (DEAB), an ALDH-specific inhibitor (StemCell Technologies, Inc.). Flow cytometry was performed using BD FACSAria.

Assay to determine sensitivity to chemotherapydrugs, with or without verapamil. To assess the sensitivity of NMFH-1 cells to cisplatin (CDDP) and doxorubicin (DXR), which are frequently used for chemotherapy in patients with sarcoma, the NMFH-1 cells were dissociated and inoculated into 96-well microtiter plates (Corning Inc.) at a concentration of 2,000 cells $/ 90 \mu \mathrm{l} / \mathrm{well}$. The cells were allowed to attach to the plates in RPMI-1640 supplemented with $10 \% \mathrm{FBS}$ at $37^{\circ} \mathrm{C}$. Subsequent to $12 \mathrm{~h}$ incubation, the cells were then exposed to various concentrations of CDDP or DXR $(1,5,10 \mu \mathrm{M})$ with or without $50 \mu \mathrm{M}$ verapamil. Following $48 \mathrm{~h}$ incubation, with or without chemotherapy drugs, the cell viability was measured by MTS assay using CellTiter 96 Aqueous One Solution Cell Proliferation Assay reagent (Promega, Madison, WI, USA), according to the manufacturer's instructions. This was compared with the control cells, which were incubated without drugs. NMFH-1 cells were then inoculated into 96-well ultra low attachment microplates (Corning, Inc.) in RPMI-1640 supplemented with B27 with $1 \%$ methylcellulose medium at a concentration of 5,000 cells/90 $\mu \mathrm{l} /$ well for 10 days to allow sphere formation. The cells were then treated with CDDP or DXR at a final concentration of 1,5 or $10 \mu \mathrm{M}$, with or without $50 \mu \mathrm{M}$ verapamil, and subsequently cell viability was measured by MTS assay following $48 \mathrm{~h}$ of treatment.

Reverse transcription-polymerase chain reaction ( $R T-P C R)$. Total RNA was extracted from frozen packed cells using the RNeasy Total RNA system (Qiagen GmbH, Hilden, Germany) and first-strand cDNA was synthesized from 500 ng samples using the Superscript II RNase H Reverse Transcriptase system (Invitrogen Life Technologies). PCR was performed using $0.5 \mu \mathrm{l}$ reaction mixture as templates. The primer sequences used for the amplification of the Nanog, Oct3/4, signal transducer and activator of transcription 3 (STAT3), sex determining region Y-box 10 (SOX10) 
Table I. Primer sets for reverse transcription-polymerase chain reaction.

\begin{tabular}{lll}
\hline Gene & \multicolumn{1}{c}{ Forward, 5'-3' } & \multicolumn{1}{c}{ Reverse, 5'-3' } \\
\hline Nanog & GCTGAGATGCCTCACACGGAG & TCTGTTTCTTGACTGGGACCTTGTC \\
Oct3/4 & TGGAGAAGGAGAAGCTGGAGCAAAA & GGCAGATGGTCGTTTGGCTGAATA \\
STAT3 & GGGTGGAGAAGGACATCAGCGGTAA & GCCGACAATACTTTCCGAATGC \\
SOX10 & TATATACGACACTGTCCCGGC & AGTGTGGGTGCAACAGTCAAC \\
ABCG2 & ACCTGAAGGCATTTACTGAA & TCTTTCCTTGCAGCTAAGAC \\
GAPDH & CAGCCGAGCCACATCG & TGAGGCTGTTGTCATACTTCT
\end{tabular}

STAT3, signal transducer and activator of transcription 3; SOX10, sex determining region Y-box 10; ABCG2, adenosine triphosphate-binding cassette sub-family G member 2 .

and ABCG2 genes are listed in Table I. The GAPDH gene was used as an internal control to adjust the quantities of the template. Aliquots of amplification products $(10 \mu \mathrm{l})$ were separated by electrophoresis in $1.5 \%$ agarose gels and visualized by ethidium bromide staining (Qiagen $\mathrm{GmbH}$, Hilden, Germany).

Western blotting. The cells were lysed in $50 \mathrm{mM}$ Tris- $\mathrm{HCl}$ (pH 7.4), $150 \mathrm{mM} \mathrm{NaCl}, 1 \mathrm{mM}$ EDTA, $1 \%$ NP-40, $0.1 \%$ SDS, $1 \%$ Na-deoxycholate, $1 \mathrm{mM}$ Na-vanadate, and protease inhibitors consisting of $5 \mathrm{mg} / \mathrm{ml}$ pepstatin, $1 \mathrm{mM}$ phenylmethylsulfonyl fluoride, $10 \mathrm{mg} / \mathrm{ml}$ leupeptin and $1 \mathrm{mM}$ NaF (Sigma-Aldrich) for $1 \mathrm{~h}$ in ice. Following centrifugation at $13,000 \mathrm{x}$ for $10 \mathrm{~min}$ at $4^{\circ} \mathrm{C}$, the protein concentration of the supernatants was measured using a bicinchoninic acid protein assay kit (Pierce, Rockford, IL, USA). The lysates were mixed with Laemmli buffer (dilution, 1:1; Sigma-Aldrich). In total, $50 \mu \mathrm{g}$ of protein per lane was electrophoresed in $10 \%$ SDS polyacrylamide gels and transferred onto polyvinylidene difluoride membranes (Sigma-Aldrich). The membranes were blocked with non-fat milk for $1 \mathrm{~h}$ at room temperature and incubated overnight at $4^{\circ} \mathrm{C}$ with rabbit monoclonal anti-CD44 (dilution, 1:2,000; ab51037, Abcam, Cambridge, MA, USA), rabbit polyclonal anti-CD133 (dilution, 1:1,000; SAB2107606, Sigma-Aldrich) and rabbit polyclonal IgG anti-GAPDH (dilution, 1:5,000; sc-25778, Santa Cruz Biotechnology, Inc., Dallas, TX, USA) in $5 \%$ bovine albumin (Sigma-Aldrich), Tris-buffered saline (TBS) and 0.1\% Tween-20 (Bio-Rad Laboratories, Hercules, CA, USA). Subsequent to being washed three times in TBS with $0.1 \%$ Tween-20, the blots were incubated with Goat anti-rabbit IgG (5366S; Cell Signaling Technology, Danvers, MA, USA; Jackson ImmunoResearch Laboratories, Inc., West Grove, PA, USA). Immunoreactive bands were detected by ECL Plus SuperSignal West Pico (Thermo Fisher Scientific, Inc., Waltham, MA, USA) for $60 \mathrm{sec}$.

Statistical analysis. The data are expressed as the mean \pm standard deviation. The $\chi^{2}$ test and Fisher's exact test were used where appropriate $(n>40$ and $n<40$, respectively). All statistical analyses were performed using SPSS 13.0 statistical software (SPSS, Inc., Chicago, IL, USA). $\mathrm{P}<0.05$ was considered to indicate a statistically significant difference.

\section{Results}

Detection of SP cells in human sarcoma cell lines. The present study aimed to detect the proportion of the SP cells in bone and soft tissue sarcoma cell lines. The NMFH-1 (Fig. 1A) and HT1080 (Fig. 1B) cell lines consisted of 0.3 and $1.08 \%$ SP cells, respectively. In each cell line, the percentage of SP cells was markedly diminished by treatment with verapamil, which is an inhibitor of the protein pumps, such as ABCG2, responsible for the exclusion of Hoechst 33342 dye, indicating that this population accurately indicated the proportion of SP cells. However, staining of the synovial sarcoma SW982 cells did not reveal the presence of SP cells, which was either due to inappropriate culture conditions or the cells lacking a stem cell population that was able to be defined. Therefore, the NMFH-1 cells, which contained the highest proportion of SP cells, was selected and underwent additional analysis.

ALDH $H^{+}$populations of NMFH-1 cells. The presence and size of the cell populations that demonstrated ALDH enzymatic activity were assessed in NMFH-1 cells using an Aldefluor assay. The results revealed that NMFH-1 cells contained populations of cells exhibiting ALDH activity, with a frequency of $8.2 \%$ in NMFH-1 cells (Fig. 2A), compared to the frequency of $0.4 \%$ in the control NMFH-1 cells treated with the ALDH inhibitor DEAB (Fig. 2B).

Spherical colony formation in NMFH-1 cells. The ability of NMFH-1 cells to generate spherical clones and self-renew was evaluated in a serum-starved culture assay. To investigate cell self-renewal, cultured spheres were dissociated into single cells and allowed to grow in monolayer culture and serum-starved anchorage-independent conditions with $1 \%$ methylcellulose medium: This process was repeated twice. The spherical colonies of NMFH-1 cells revealed expansion in the monolayer culture, which led to cell differentiation and self-renewal through the secondary formation of spherical colonies (Fig. 3).

Chemotherapy drug resistance between NMFH-1 and spherical colonies. CDDP and DXR inhibited the growth of NMFH-1 cells in a dose-dependent manner. The survival rates of adherent and spherical colonies subsequent to 48-h drug treatment are shown in Table II and Figs. 4-6. The difference in the growth inhibition rate between the adherent and spherical 
Table II. Cell survival rates of NMFH-1 cells subsequent to $48 \mathrm{~h}$ treatment with CDDP, with or without $50 \mu \mathrm{M}$ verapamil.

Cell survival rate, $\%$

Treatment

Adherent colony

Spherical colony

$\chi^{2}$

P-value

CDDP

\begin{tabular}{lllll}
$1 \mu \mathrm{M}$ & $83.91 \pm 3.98$ & $98.97 \pm 0.40$ & 446 & 0.0004 \\
$5 \mu \mathrm{M}$ & $64.38 \pm 11.15$ & $87.80 \pm 12.10$ & 337 & 0.0024 \\
$10 \mu \mathrm{M}$ & $50.17 \pm 13.57$ & $83.76 \pm 14.05$ & 279 & 0.0003 \\
CDDP + verapamil & & & \\
$1 \mu \mathrm{M}$ & $64.18 \pm 14.37$ & $96.39 \pm 6.21$ & 370 & 0.0001 \\
$5 \mu \mathrm{M}$ & $46.29 \pm 14.68$ & $74.40 \pm 16.62$ & 259 & 0.0016 \\
$10 \mu \mathrm{M}$ & $43.39 \pm 12.01$ & $69.40 \pm 16.09$ & 241 & 0.0001 \\
\hline
\end{tabular}

Values are expressed as the mean \pm standard deviation. ${ }^{a} \mathrm{P}<0.05$. CDDP, cisplatin.
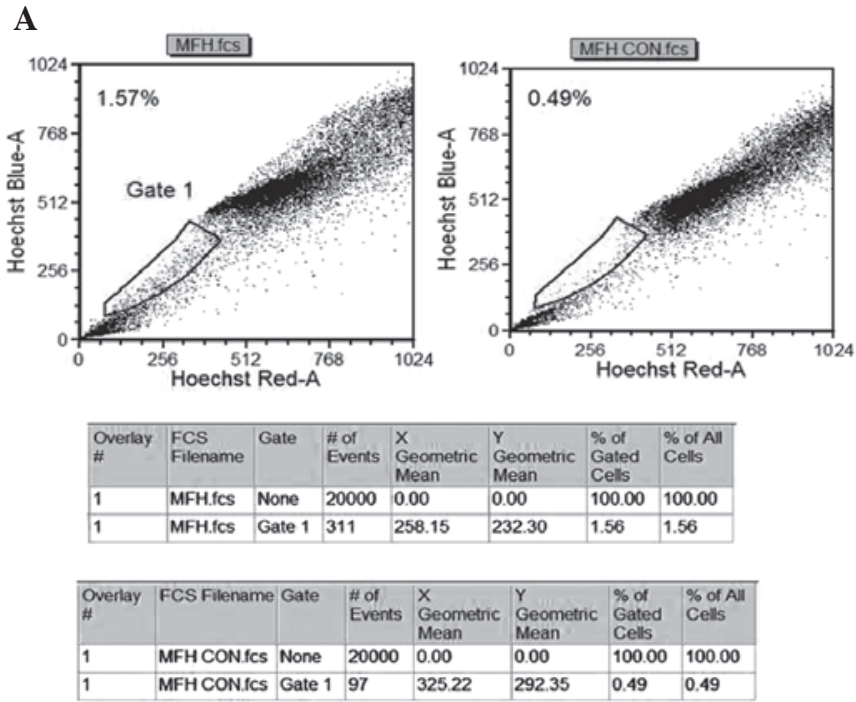

B
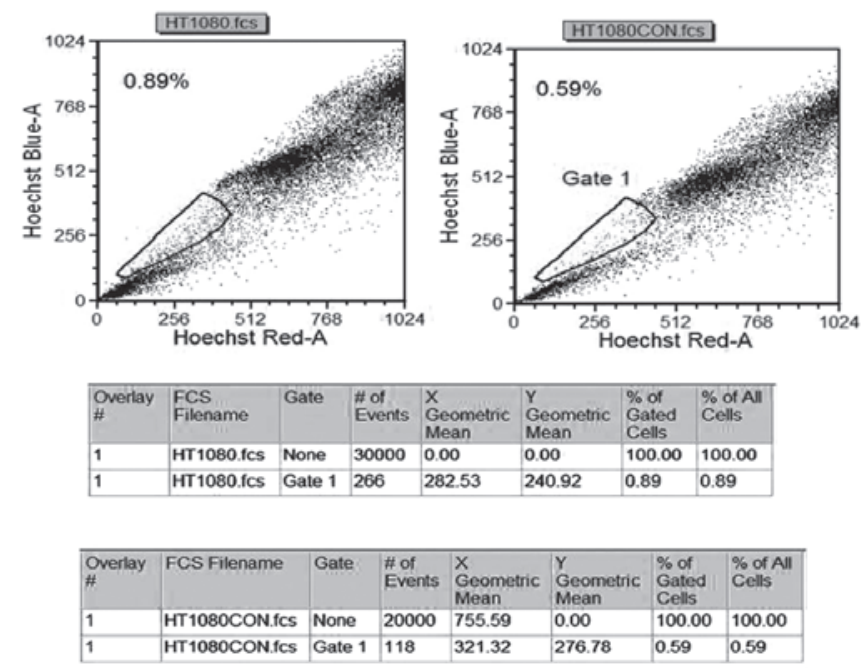

Figure 1. Detection of SP cells in human sarcoma cell lines. Proportion of the SP cells in the (A) malignant fibrous histiocytoma NMFH-1 cell line and (B) fibrosarcoma HT1080 cell line. SP, side population

colonies was statistically significant $(\mathrm{P}=0.0003)$, as $10 \mu \mathrm{M}$ of CDDP inhibited cell growth by $50 \%$ in NMFH-1 cells in monolayer culture and $23 \%$ in sphere conditions, respectively. In addition, $10 \mu \mathrm{M}$ DRX inhibited cell growth by $58 \%$ in adherent conditions and by $31 \%$ in spherical colony conditions. These results suggest that the spherical colonies are resistant to CDDP and DXR, which are the most commonly available chemotherapy drugs for sarcomas. The application of verapamil, an ABCG2 inhibitor, in combination with either CDDP or DXR resulted in increased cell growth inhibition compared with non-verapamil treatment. However, the growth inhibition rates were limited to only $26.8 \%$ for CDDP combined with verapamil and $31.1 \%$ for DXR combined with verapamil in adherent conditions. In spherical conditions, the growth inhibition rates were $19.4 \%$ for CDDP combined with verapamil and $25.5 \%$ for DXR combined with verapamil.

Expression of Nanog, Oct3/4, STAT3, SOX10 and ABCG2. The expression of the STAT3, Nanog, Oct3/4, Sox 10 and
ABCG2 genes, all of which are associated with the marker genes of pluripotent ES cells, was investigated by semi-quantitative RT-PCR analysis to determine whether these genes were expressed in adherent and sphere formation conditions. All five genes were expressed in spherical NMFH-1 cell colonies, and the spheres consistently demonstrated increased expression of these genes, with the exception of Nanog, compared with adherent cells (Fig. 7). ABCG2 encodes a membrane efflux transporter that is expressed in human hematopoietic stem cells (2), and the gene is also associated with chemotherapy resistance $(18,25)$. The protein encoded by ABCG 2 functions as a xenobiotic transporter, which may play a major role in multi-drug resistance. The ABCG2 protein is likely to act as a cellular defense mechanism in response to exposure to mitoxantrone and anthracycline (26). ABC transporters have the capacity to export numerous chemotherapy agents and are upregulated in CSCs derived from certain cancer cell lines $(17,18)$. In particular, ABCG2 has been implicated in the high Hoechst 33342 dye efflux capacity 
A

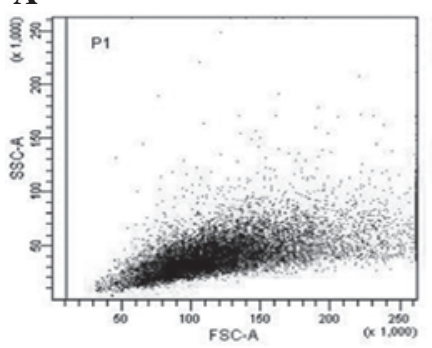

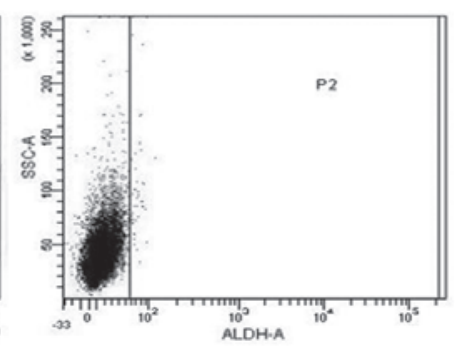
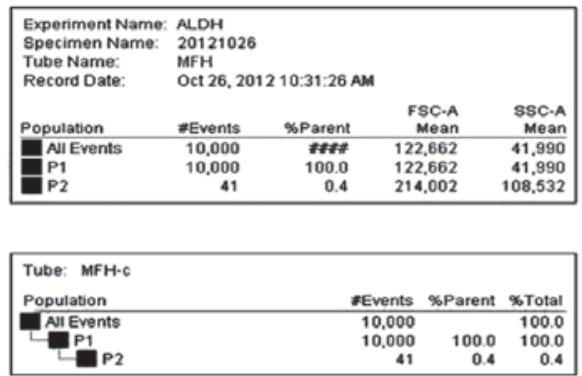

B
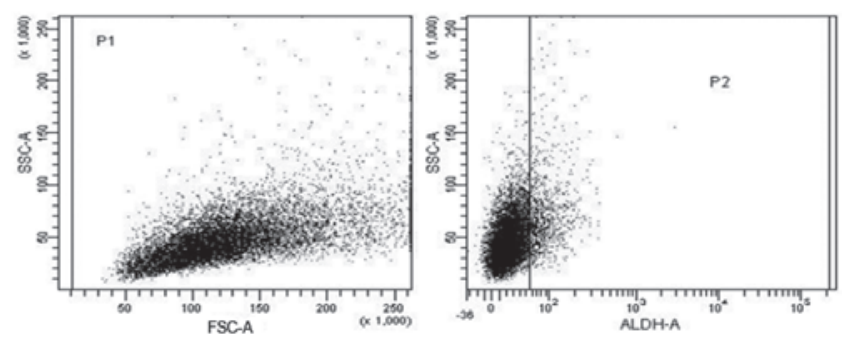

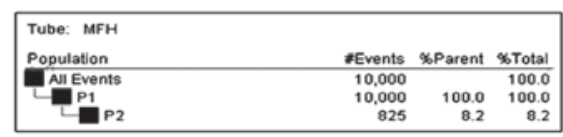

Figure 2. Cell populations expressing ALDH in the NMFH-1 cell line. (A) Fluorescence-activated cell sorting analysis of NMFH-1 cells, using the ALDH inhibitor 4-diethylaminobenzaldehyde as a control. (B) Aldefluor assay demonstrating that $8.2 \%$ of the human NMFH-1 cell population exhibits high ALDH1 activity. ALDH, aldehyde dehydrogenase.

A

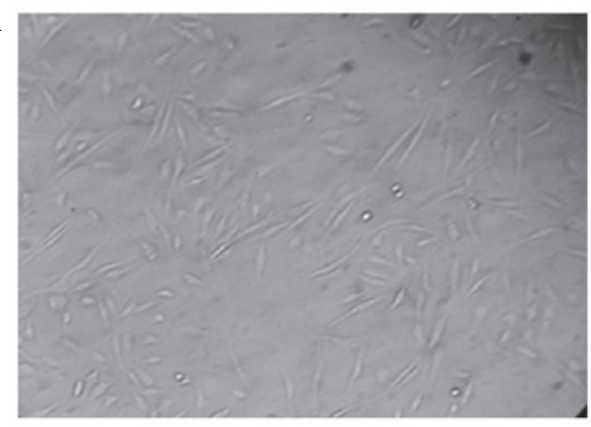

C

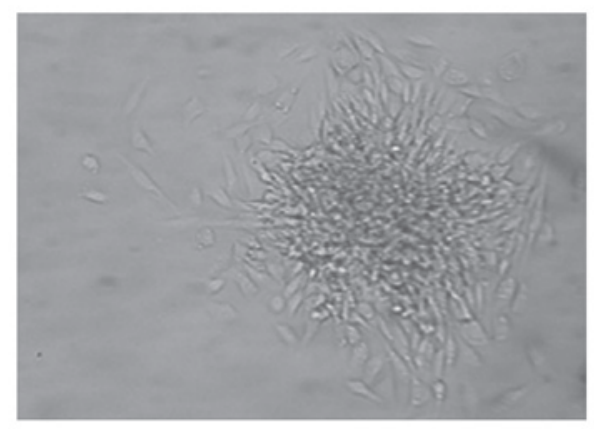

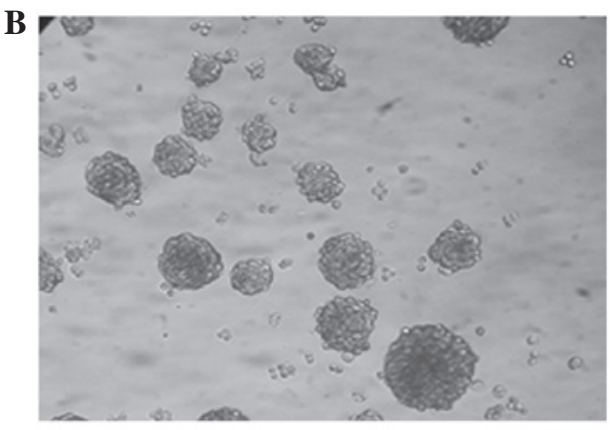

D

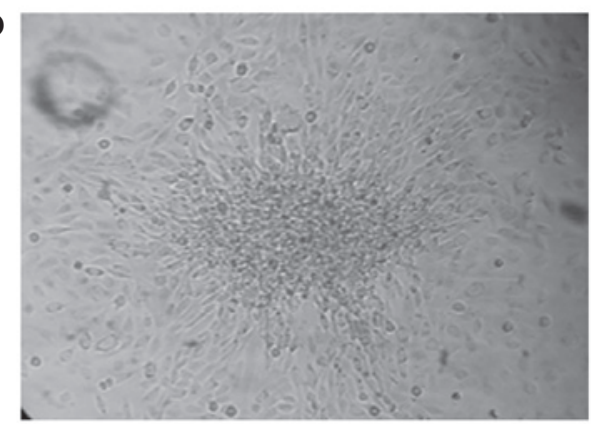

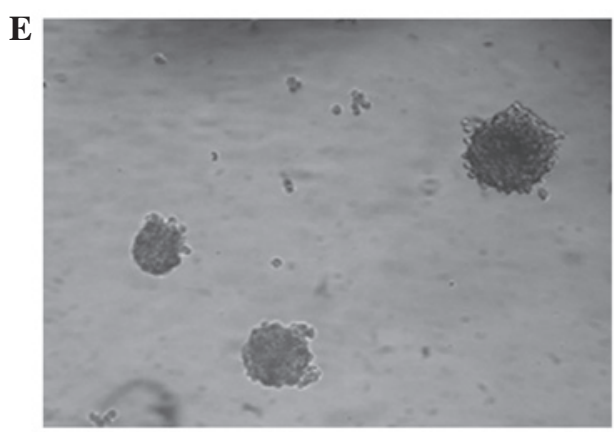

Figure 3. Spherical colony formation in NMFH-1 cells. Microscopic appearance of (A) NMFH-1 cells in the monolayer conditions and (B) spherical colony formation in anchorage-independent, serum-starved conditions subsequent to 12 days. (C and D) The spherical colonies were removed from the suspension culture and allowed to attach to a substratum. The adherent cells can be observed expanding from the sphere. (E) Secondary formation of spherical colonies was achieved by repeatly seeding into anchorage-independent, serum-starved conditions. 


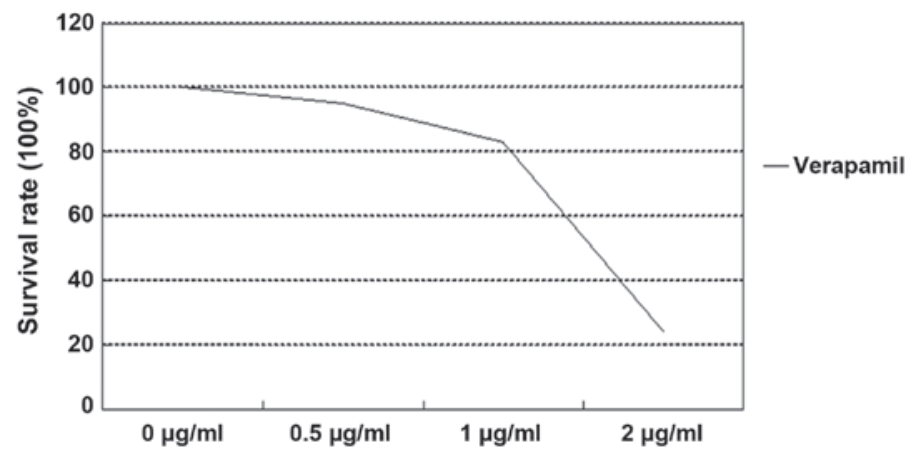

Figure 4. Resistance to chemotherapy drugs in spherical colonies of NMFH-1 cells. NMFH-1 cell growth was suppressed by verapamil in a dose-dependent manner. The cell growth inhibition rates was $1.2 \%$ at a concentration of $0.5 \mu \mathrm{g} / \mathrm{ml}(50 \mu \mathrm{M})$ verapamil.

A

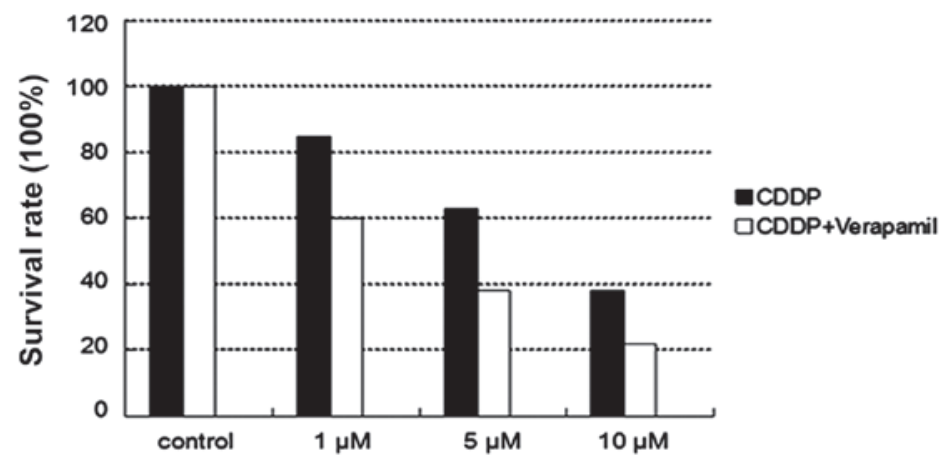

B

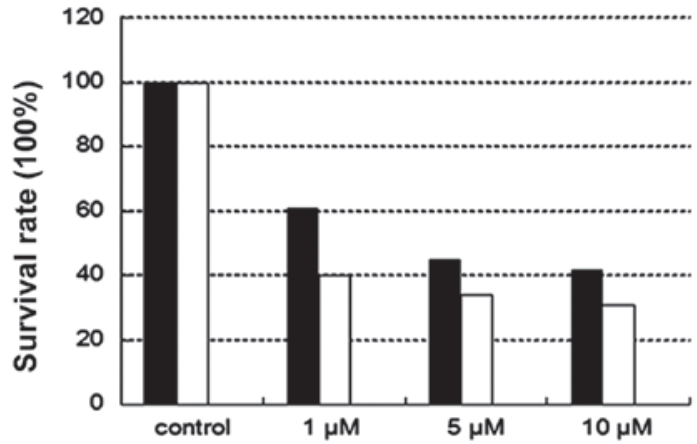

DDR

DDXR+Verapami

Figure 5. Cell growth of NMFH-1 cells was suppressed by (A) CDDP and (B) DXR in a dose-dependent manner. The growth inhibition rates exerted by $10 \mu \mathrm{M}$ CDDP and $10 \mu \mathrm{M}$ DXR were 50 and 58\%, respectively. The application of verapamil, an inhibitor of adenosine triphosphate-binding cassette sub-family G member 2, in combination with the chemotherapy drugs increased the efficacy of the drugs. However, the effects were limited to a growth inhibition rate of $26.8 \%$ in CDDP-treated cells and $31.1 \%$ in DXR-treated cells. The data was obtained at a concentration of $50 \mu \mathrm{M}$ verapamil in conjunction with $1 \mu \mathrm{M}$ of CDDP and DXR. Similar results were obtained from treatment with 5 and $10 \mu \mathrm{M}$ CDDP or DXR with verapmil. CDDP, cisplatin; DXR, doxorubicin.

that marks the SP cell phenotype. Therefore, to investigate abundance of $\mathrm{ABC}$ transporters associated with multi-drug resistance, RT-PCR was used to determine the relative mRNA expression of ABC transporters in NMFH-1 adherent and spherical cell colonies.

Expression of CD44 and CD133. The expression of the normal stem-associated cell proteins and candidate CSC markers CD133 and CD44 was examined by western blotting. The results revealed that the expression of the two proteins in the spherical colonies was significantly increased compared with the expression in the adherent NMFH-1 cells (Fig. 8), indicating that the spherical colonies possess certain stem cell-like properties. However, the expression of CD44 was considerably increased in the adherent and spherical colony formation conditions, which suggests that NMFH-1 cells may demonstrate a considerable migratory ability, as CD44 induces a metastatic phenotype in locally growing tumor cells $(27,28)$. These results indicate that the spherical colony formation system may increase the expression of CD44 and CD133 in stem and progenitor cells.

\section{Discussion}

In general, there are two models of heterogeneity in cancer cells $(1,29)$. The first model is that cancer cells of numerous phenotypes have the potential to proliferate extensively, and any one cell may have a low probability of exhibiting this potential in an assay of clonogenicity or tumorigenicity (1). The second model is that the majority of cancer cells have 

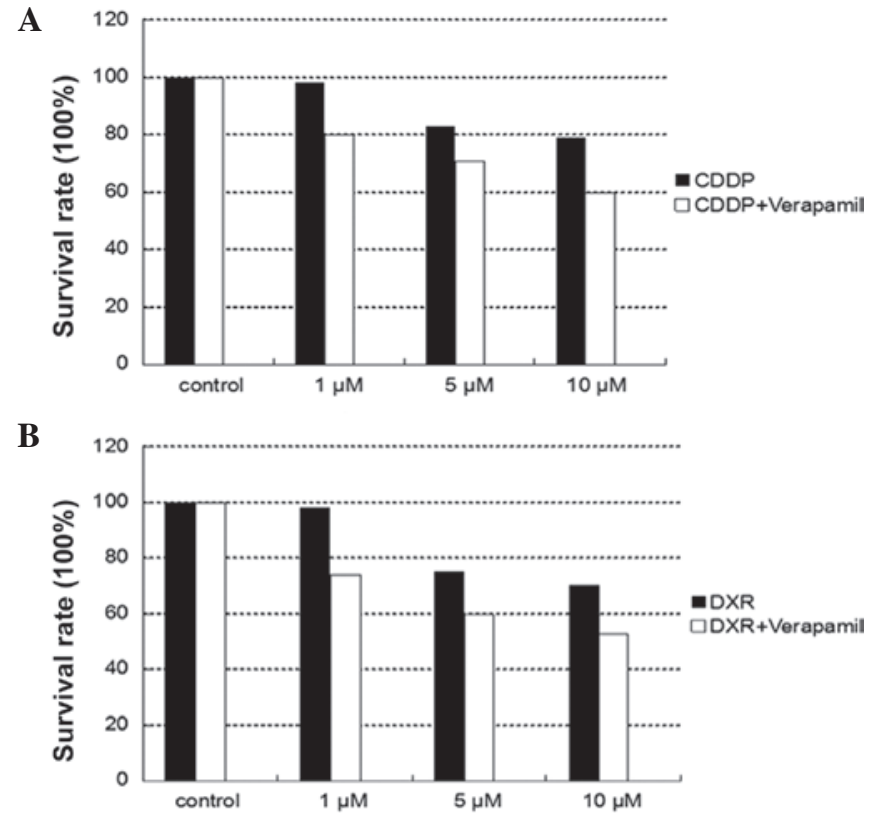

Figure 6. The growth of spherical colonies was suppressed by (A) CDDP and (B) DXR in a dose-dependent manner. The growth inhibition rates induced by $10 \mu \mathrm{M}$ CDDP and $10 \mu \mathrm{M}$ DXR were $23 \%$ and $31 \%$, respectively. The application of verapamil in combination with drugs increased the efficacy of chemotherapeutic drugs. However, the effects were limited to $18.6 \%$ for CDDP and $22.3 \%$ for DXR. The data was obtained at a concentration of $50 \mu \mathrm{M}$ verapamil with $1 \mu \mathrm{M}$ CDDP or $1 \mu \mathrm{M}$ DXR. Similar results were obtained from treatmetn with $10 \mu \mathrm{M}$ CDDP or $10 \mu \mathrm{M}$ DXR with verapmil. CDDP, cisplatin; DXR, doxorubicin.

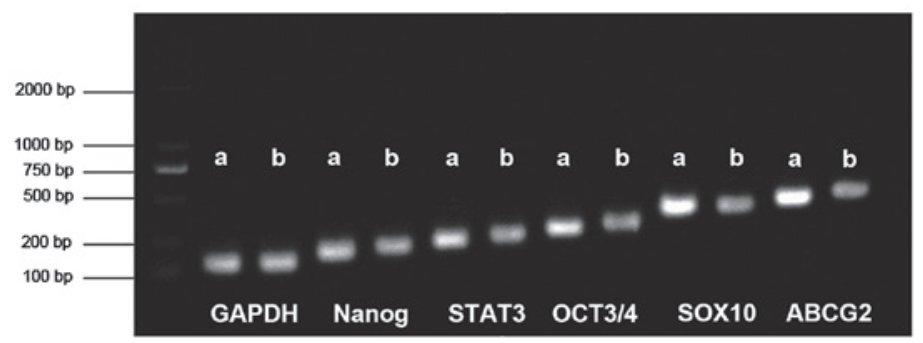

Figure 7. Expression of Nanog, OCT3/4, STAT3, SOX10 and ABCG2. Reverse transcription-polymerase chain reaction revealed strong expression of Nanog, STAT3, OCT3/4, SOX10 and ABCG2 in spherical NMFH-1 cell colonies, compared with the adherent cells. a, spherical colonies; b, adherent cells; STAT3, signal transducer and activator of transcription 3; SOX10, sex determining region Y-box 10; ABCG2, adenosine triphosphate-binding cassette sub-family G member 2 .

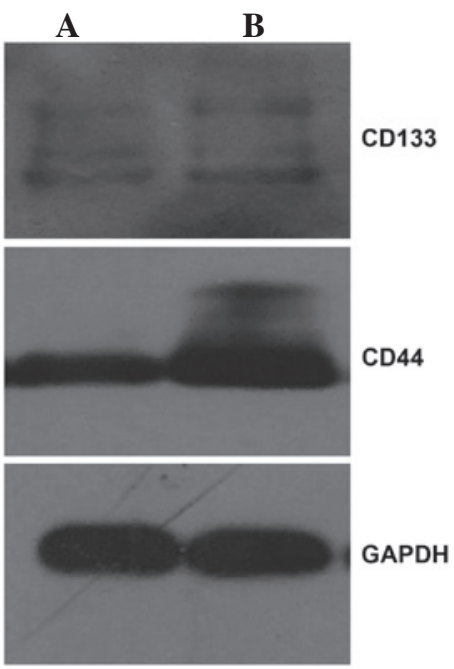

Figure 8. Expression of CD44 and CD133 in (A) adherent cells and (B) spherical colonies of NMFH-1 cells. Western blotting revealed strong expression of CD44 and CD133 in spherical colonies of NMFH-1 cells compared with the expression in adherent cells. CD, cluster of differentiation. only limited proliferative potential, and only a rare subset of cancer cells consistently proliferates extensively in clonogenic assays and may form novel tumors on transplantation (29). This model predicts that a distinct subset of cells demonstrates an increased ability to form novel tumors, whereas the majority of cells do not possess this ability. Previous therapeutic failure to successfully treat the majority of cancers indicates that the second model of heterogeneity may be the more accurate model. The CSC hypothesis is consistent with the latter model that tumors contain a small subpopulation of cancer cells that share numerous stem cell-like properties, including proliferative potential and self-renewal, increased or decreased expression of stem cell-associated genes and cell surface markers. These rare stem cell-like tumor initiators are considered to be associated with initiating and maintaining the growth of tumors, and these cells may be responsible for local recurrence and distant metastasis.

In the present study, the novel myxofibrosarcoma cell line NMFH-1 was demonstrated to possess the abilities to form 
spherical colonies and self-renewal in anchorage-independent, serum-starved culture conditions, which were previously developed to isolate cancer stem cells from hepatoma and certain bone sarcomas $(6,7,20,23)$. The present study found that NMFH-1 adherent cells and spherical colonies expressed key marker genes of ES cells, consisting of Nanog, STAT3, Oct $3 / 4$ and SOX10. However, increased expression of STAT3, Oct $3 / 4$ and SOX10 was identified in spherical colonies compared with the adherent cultures. These genes play important roles in ES cells. Nanog maintains self-renewal in ES cells $(30,31)$, STAT3 plays important roles in regulating cell growth, differentiation, apoptosis, angiogenesis and immune responses (32), SOX10 is involved in the regulation of embryonic development and the determination of cell fate (33), and Oct $3 / 4$ is a POU domain, octamer-binding transcription factor that is expressed in ES cells (34). In particular, previous studies have revealed that the increased or decreased expression of these stem cell-associated genes have been found in numerous primary cancers and CSCs $(6,7,21,23,35)$. Therefore, certain key marker genes in ES cells may play a role in sarcoma oncogenesis.

To investigate the CSC properties of spherical colonies, the sensitivity of spherical colonies to chemotherapy agents was investigated. The spherical colonies exhibited general resistance to CDDP and DXR, and demonstrated increased survival ability compared with the adherent cells. In addition, verapamil, an ABCG2 inhibitor, in combination with either CDDP or DXR, demonstrated an increased inhibition of cell growth compared with non-verapamil treatment. It has been demonstrated that $\mathrm{ABC}$ transporters have the capacity to export numerous chemotherapy agents and are upregulated in CSCs derived from certain cancer cell lines $(17,18)$. The $\mathrm{ABCG} 2$ protein functions as a xenobiotic transporter that may play a major role in multi-drug resistance (2). This protein is likely to act as a cellular defense mechanism in response to the exposure of cells to mitoxantrone and anthracycline (26), and is alternatively referred to as a breast cancer resistance protein (36). The present results indicate that verapamil may enhance the efficacy of chemotherapy agents by inhibiting ABCG2 from pumping chemotherapy drugs out of the cells. However, the ABCG2 inhibitor verapamil may only partially inhibit the growth adherent cells and spherical colonies. This may be due to cancer stem cells expressing other drug resistant proteins, including ABCB1 (37).

Furthermore, the present study demonstrated that the spherical colony culture system may enrich stem-like cells with the expression of the ABCG2 gene, according to the present results from RT-PCR. Previous studies have revealed that the ABCG2 gene is highly expressed in the placenta, normal stem cells and in certain tumor stem cells $(2,38-40)$. ABCG2 levels were reduced when stem cells were induced to differentiate. In particular, ABCG2 has been implicated in the high Hoechst 33342 dye efflux capacity that is characteristic of the SP phenotype, and was subsequently identified and characterized as a novel stem cell marker (39). Thus, the spherical colonies overexpress ABCG2 and are more resistant to CDDP and DXR, indicating a possible contribution of these cells to cancer chemoresistance.

Finally, the expression of the candidate CSC markers CD44 and CD133 was examined in the spherical colonies. The lymphocyte homing receptor CD44 is expressed in numerous cells and is considered to be a cell-surface glycoprotein involved in cell-cell interactions, cell adhesion and migration (41). In particular, CD44 induces a metastatic phenotype in locally growing tumor cells $(27,28)$. There is considerable evidence for the contribution of CD44 expression to the initiation and progression of numerous tumors and CSCs (42). CD133 is an important candidate CSC marker that localizes to membrane protrusions and is often expressed on adult stem cells, where it is hypothesized to maintaining stem cell properties by suppressing differentiation. CD133 has been used as a marker for hematopoietic stem cells (43) and neuronal stem cells (44). Previously, various studies have demonstrated that CD133 is associated with the initiation and progression of cancer stem and progenitor cells, and may be a valuable CSC marker in a variety of tumors, including epithelial cancers and solid sarcomas $(10,11,45-50)$. Therefore, the increased expression of CD44 and CD133 in NMFH-1 spherical colonies may account for the increased survival and metastatic ability of these cells.

In conclusion, the present study revealed that the spherical colonies derived from NMFH-1 cells demonstrate stem-like properties in anchorage-independent conditions, and it was indicated that spherical colonies may contain CSC subpopulations. The current findings support the hypothesis that human NMFH-1 cells are heterogeneous, and that rare cells within the bulk of a tumor are responsible for the initiation and growth of NMFH-1 lesions. Due to the current inability to successfully treat the majority of tumors, the modulations of drug resistance in cancer chemotherapy may be promising. ABC transporter protein inhibitors, such as verapamil, may be valuable candidates. In addition, as CD44 plays an important role in tumor growth, progression and metastasis, the present interest in the use of CDs in tumor therapy should be increased.

\section{Acknowledgements}

This study was supported by the National Natural Science Foundation of China (grant nos. 30772205 and 81472512) and the Research Fund for Science and Technology Innovation Talents, Harbin Science and Technology Bureau (grant no. 2007RFLXS024). The authors thank Dr. Akira Ogose (Division of Orthopedic Surgery, Niigata University Graduate School of Medical and Dental Sciences, Niigata, Japan) for providing the NMFH-1 cell line.

\section{References}

1. Reya T, Morrison SJ, Clarke MF and Weissman IL: Stem cells, cancer and cancer stem cells. Nature 414: 105-111, 2001.

2. Scharenberg CW, Harkey MA and Torok-Storb B: The ABCG2 transporter is an efficient Hoechst 33342 efflux pump and is preferentially expressed by immature human hematopoietic progenitors. Blood 99: 507-512, 2002

3. Singh SK, Hawkins C, Clarke ID, Squire JA, Bayani J, Hide T, Henkelman RM, Cusimano MD and Dirks PB: Identification of human brain tumour initiating cells. Nature 432: 396-401, 2004.

4. Ponti D, Costa A, Zaffaroni N, Pratesi G, Petrangolini G, Coradini D, Pilotti S, Pierotti MA and Daidone MG: Isolation and in vitro propagation of tumorigenic breast cancer cells with stem/progenitor cell properties. Cancer Res 65: 5506-5511, 2005.

5. Fang D, Nguyen TK, Leishear K, Finko R, Kulp AN, Hotz S, Van Belle PA, Xu X, Elder DE and Herlyn M: A tumorigenic subpopulation with stem cell properties in melanomas. Cancer Res 65: 9328-9337, 2005. 
6. Fujii H, Honoki K, Tsujiuchi T, Kido A, Yoshitani K and Takakura Y: Sphere-forming stem-like cell populations with drug resistance in human sarcoma cell lines. Int J Oncol 34: 1381-1386, 2009.

7. Gibbs CP, Kukekov VG, Reith JD, Tchigrinova O, Suslov ON, Scott EW, Ghivizzani SC, Ignatova TN and Steindler DA: Stem-like cells in bone sarcomas: Implications for tumorigenesis. Neoplasia 7: 967-976, 2005.

8. Naka N, Takenaka S, Araki N, Miwa T, Hashimoto N, Yoshioka K, Joyama S, Hamada K, Tsukamoto Y, Tomita Y, et al: Synovial sarcoma is a stem cell malignancy. Stem Cells 28: 1119-1131, 2010.

9. Zoller M: CD44: Can a cancer-initiating cell profit from an abundantly expressed molecule? Nat Rev Cancer 11: 254-267, 2011.

10. Jiang X, Gwye Y, Russell D, Cao C, Douglas D, Hung L, Kovar H, Triche TJ and Lawlor ER: CD133 expression in chemo-resistant Ewing sarcoma cells. BMC Cancer 10: 116, 2010.

11. Wang Q, Chen ZG, Du CZ, Wang HW, Yan L and Gu J: Cancer stem cell marker CD133+ tumour cells and clinical outcome in rectal cancer. Histopathology 55: 284-293, 2009.

12. Dean M, Fojo T and Bates S: Tumour stem cells and drug resistance. Nat Rev Cancer 5: 275-284, 2005

13. Korkaya $\mathrm{H}$ and Wicha MS: Selective targeting of cancer stem cells: A new concept in cancer therapeutics. BioDrugs 21: 299-310, 2007

14. Bonnet D and Dick JE: Human acute myeloid leukemia is organized as a hierarchy that originates from a primitive hematopoietic cell. Nat Med 3: 730-737, 1997.

15. Al-Hajj M, Wicha MS, Benito-Hernandez A, Morrison SJ and Clarke MF: Prospective identification of tumorigenic breast cancer cells. Proc Natl Acad Sci USA 100: 3983-3988, 2003.

16. Honoki K, Fujii H, Kubo A, Kido A, Mori T, Tanaka Y and Tsujiuchi T: Possible involvement of stem-like populations with elevated ALDH1 in sarcomas for chemotherapeutic drug resistance. Oncol Rep 24: 501-505, 2010.

17. Yang M, Zhang R, Yan M, Ye Z, Liang W and Luo Z: Detection and characterization of side population in Ewing's sarcoma SK-ES-1 cells in vitro. Biochem Biophys Res Commun 391: 1062-1066, 2010

18. Hirschmann-Jax C, Foster AE, Wulf GG, Nuchtern JG, Jax TW Gobel U, Goodell MA and Brenner MK: A distinct 'side population' of cells with high drug efflux capacity in human tumor cells. Proc Natl Acad Sci USA 101: 14228-14233, 2004.

19. Reynolds BA and Weiss S: Generation of neurons and astrocytes from isolated cells of the adult mammalian central nervous system. Science 255: 1707-1710, 1992.

20. Wilson H, Huelsmeyer M, Chun R, Young KM, Friedrichs K and Argyle DJ: Isolation and characterisation of cancer stem cells from canine osteosarcoma. Vet J 175: 69-75, 2008

21. Zhong Y, Guan K, Guo S, Zhou C, Wang D, Ma W, Zhang Y, Li C and Zhang S: Spheres derived from the human SK-RC-42 renal cell carcinoma cell line are enriched in cancer stem cells. Cancer Lett 299: 150-160, 2010.

22. Murase M, Kano M, Tsukahara T, Takahashi A, Torigoe T, Kawaguchi S, Kimura S, Wada T, Uchihashi Y, Kondo T, et al: Side population cells have the characteristics of cancer stem-like cells/cancer-initiating cells in bone sarcomas. Br J Cancer 101: 1425-1432, 2009

23. Cao L, Zhou Y, Zhai B, Liao J, Xu W, Zhang R, Li J, Zhang Y, Chen L, Qian H, et al: Sphere-forming cell subpopulations with cancer stem cell properties in human hepatoma cell lines. BMC Gastroenterol 11: 71, 2011.

24. Kawashima H, Ogose A, Gu W, Nishio J, Kudo N, Kondo N, Hotta T, Umezu H, Tohyama T, Nishijima H, et al: Establishment and characterization of a novel myxofibrosarcoma cell line. Cancer Genet Cytogenet 161: 28-35, 2005.

25. Goodell MA, Brose K, Paradis G, Conner AS and Mulligan RC: Isolation and functional properties of murine hematopoietic stem cells that are replicating in vivo. J Exp Med 183: 1797-1806, 1996

26. Sharom FJ: ABC multidrug transporters: Structure, function and role in chemoresistance. Pharmacogenomics 9: 105-127, 2008.

27. Gunthert U, Hofmann M, Rudy W, Reber S, Zöller M, Haussmann I, Matzku S, Wenzel A, Ponta H and Herrlich P: A new variant of glycoprotein CD44 confers metastatic potential to rat carcinoma cells. Cell 65: 13-24, 1991.

28. Naor D, Wallach-Dayan SB, Zahalka MA and Sionov RV: Involvement of CD44, a molecule with a thousand faces, in cancer dissemination. Semin Cancer Biol 18: 260-267, 2008.
29. Michelson S and Slate D: Emergence of the drug-resistant phenotype in tumor subpopulations: A hybrid model. J Natl Cancer Inst 81: 1392-1401, 1989.

30. Chambers I, Colby D, Robertson M, Nichols J, Lee S, Tweedie S and Smith A: Functional expression cloning of Nanog, a pluripotency sustaining factor in embryonic stem cells. Cell 113: 643-655, 2003

31. Mitsui K, Tokuzawa Y, Itoh H, Segawa K, Murakami M, Takahashi K, Maruyama M, Maeda M and Yamanaka S: The homeoprotein Nanog is required for maintenance of pluripotency in mouse epiblast and ES cells. Cell 113: 631-642, 2003.

32. Darnell JE Jr: STATs and gene regulation. Science 277: 1630-1635, 1997.

33. Honore SM, Aybar MJ and Mayor R: Sox10 is required for the early development of the prospective neural crest in Xenopus embryos. Dev Biol 260: 79-96, 2003.

34. Pesce M and Schöler HR: Oct-4: Gatekeeper in the beginnings of mammalian development. Stem Cells 19: 271-278, 2001.

35. Bourguignon LY, Peyrollier K, Xia W and Gilad E: Hyaluronan-CD44 interaction activates stem cell marker Nanog, Stat-3-mediated MDR1 gene expression and ankyrin-regulated multidrug efflux in breast and ovarian tumor cells. J Biol Chem 283: 17635-17651, 2008.

36. Doyle LA, Yang W, Abruzzo LV, Krogmann T, Gao Y, Rishi AK and Ross DD: A multidrug resistance transporter from human MCF-7 breast cancer cells. Proc Natl Acad Sci USA 95: 15665-15670, 1998.

37. Shukla S, Wu CP and Ambudkar SV: Development of inhibitors of ATP-binding cassette drug transporters: Present status and challenges. Expert Opin Drug Metab Toxicol 4: 205-223, 2008.

38. Kim M, Turnquist H, Jackson J, Sgagias M, Yan Y, Gong M, Dean M, Sharp JG and Cowan K: The multidrug resistance transporter ABCG2 (breast cancer resistance protein 1) effluxes Hoechst 33342 and is overexpressed in hematopoietic stem cells. Clin Cancer Res 8: 22-28, 2002.

39. Zhou S, Schuetz JD, Bunting KD, Colapietro AM, Sampath J, Morris JJ, Lagutina I, Grosveld GC, Osawa M, Nakauchi H and Sorrentino BP: The ABC transporter Bcrp1/ABCG2 is expressed in a wide variety of stem cells and is a molecular determinant of the side-population phenotype. Nat Med 7: 1028-1034, 2001

40. Allikmets R, Schriml LM, Hutchinson A, Romano-Spica V and Dean M: A human placenta-specific ATP-binding cassette gene (ABCP) on chromosome $4 \mathrm{q} 22$ that is involved in multidrug resistance. Cancer Res 58: 5337-5339, 1998.

41. Gallatin WM, Weissman IL and Butcher EC: A cell-surface molecule involved in organ-specific homing of lymphocytes. Nature 304: 30-34, 1983.

42. Ratajczak MZ: Cancer stem cells-normal stem cells 'Jedi' that went over to the 'dark side'. Folia Histochem Cytobiol 43: 175-181, 2005.

43. Miraglia S, Godfrey W, Yin AH, Atkins K, Warnke R, Holden JT, Bray RA, Waller EK and Buck DW: A novel five-transmembrane hematopoietic stem cell antigen: Isolation, characterization and molecular cloning. Blood 90: 5013-5021, 1997.

44. Uchida N, Buck DW, He D, Reitsma MJ, Masek M, Phan TV, Tsukamoto AS, Gage FH and Weissman IL: Direct isolation of human central nervous system stem cells. Proc Natl Acad Sci USA 97: 14720-14725, 2000.

45. Collins AT, Berry PA, Hyde C, Stower MJ and Maitland NJ: Prospective identification of tumorigenic prostate cancer stem cells. Cancer Res 65: 10946-10951, 2005.

46. Singh SK, Clarke ID, Terasaki M, Bonn VE, Hawkins C, Squire J and Dirks PB: Identification of a cancer stem cell in human brain tumors. Cancer Res 63: 5821-5828, 2003

47. O'Brien CA, Pollett A, Gallinger S and Dick JE: A human colon cancer cell capable of initiating tumour growth in immunodeficient mice. Nature 445: 106-110, 2007.

48. Olempska M, Eisenach PA, Ammerpohl O, Ungefroren H, Fandrich $\mathrm{F}$ and Kalthoff $\mathrm{H}$ : Detection of tumor stem cell markers in pancreatic carcinoma cell lines. Hepatobiliary Pancreat Dis Int 6: 92-97, 2007.

49. Ossowski L and Aguirre-Ghiso JA: Dormancy of metastatic melanoma. Pigment Cell Melanoma Res 23: 41-56, 2010.

50. Suva ML, Riggi N, Stehle JC, Baumer K, Tercier S, Joseph JM, Suvà D, Clément V, Provero $\mathrm{P}$, Cironi L, et al: Identification of cancer stem cells in Ewing's sarcoma. Cancer Res 69: 1776-1781, 2009. 